\title{
Complex microseismic activity and depth-dependent stress field changes in Wakayama, southwestern Japan
}

\author{
Sumire Maeda ${ }^{1 *}$, Toru Matsuzawa ${ }^{1}$, Shinji Toda ${ }^{2}$, Keisuke Yoshida ${ }^{1}$ and Hiroshi Katao ${ }^{3}$
}

\begin{abstract}
We examined the spatial relationship between seismicity and upper crustal structure in the Wakayama region, northwestern Kii Peninsula, Japan, by investigating microearthquake focal mechanisms and the local stress field. The focal mechanisms of most events studied fall into three categories: (1) normal faulting with $\mathrm{N}$-S-oriented T-axes mainly occurring at shallow depths, (2) reverse faulting with E-W-oriented P-axes dominating at intermediate depths, and (3) strike-slip faulting with $\mathrm{N}-\mathrm{S}$-oriented T-axes and $\mathrm{E}-\mathrm{W}$-oriented P-axes mainly seen at greater depths. The stress field varies with depth: the shallow part is characterized by a strike-slip-type stress regime with $\mathrm{N}-\mathrm{S}$ tension and $\mathrm{E}-\mathrm{W}$ compression, while the deep part is characterized by an E-W compressional stress regime consistent with reverse faulting. The depth-dependent stress regime can be explained by thermal stress caused by a heat source, as expected from geophysical observations. Geologic faults, acting as weak planes, might contribute to generate shallow normal fault-type and deeper strike-slip fault-type microearthquakes.
\end{abstract}

Keywords: Microearthquake, Stress field, Heterogeneous structure, Fluid, Heat source, Geological structure

\section{Introduction}

The distribution of earthquake clusters in the shallow crust is not homogeneous and is probably controlled by the heterogeneous structure of the upper crust (e.g., Katao and Ando 1996). Earthquakes distributed along known fault planes, which probably represent weak planes in heterogeneous upper crustal structures, have been found in many locations (e.g., Lee and Stewart 1981; Wada et al. 2002). Earthquake clusters, however, are also found in locations where no active faults are known to exist; e.g., an Mj (JMA magnitude) 6.3 earthquake occurred on Awaji Island, Japan on 13 April 2013, accompanied by many aftershocks, at which location no active faults have been identified (e.g., Katao et al. 2014). Matsumoto et al. (2015) pointed out that fluid at high pore pressures in the upper crust could have generated these earthquakes. These studies suggest that earthquake

\footnotetext{
*Correspondence: maeda.sumire.q6@dc.tohoku.ac.jp

1 Graduate School of Science, Tohoku University, 6-6 Aza-Aoba, Aramaki,

Aoba-ku, Sendai 980-8578, Japan

Full list of author information is available at the end of the article
}

clusters in such unexpected locations are probably caused by unknown faults or the presence of crustal fluid and that seismic activity is controlled by heterogeneous structure in the upper crust. However, the effect of structural heterogeneity on seismic activity remains poorly known. Therefore, to investigate the role of the former in controlling the latter, we examine the spatial relationship between seismic activity and heterogeneous structure in and around Wakayama city (hereafter, "Wakayama region"), northwestern Kii Peninsula, Japan (Fig. 1).

In the Wakayama region (Figs. 1 and 2), a high rate of background seismicity has been observed since at least the mid-1900s (e.g., Yoshida and Takayama 1992), but seismic activity is very complex and its generating mechanism is poorly understood. Huzita et al. (1973) pointed out that earthquake epicenters align E-W to ENE-WSW in this area, consistent with the strike directions of tectonic lines (Fig. 2). From the distributions of earthquake clusters and the geological structure, focal mechanism solutions are expected to show strike-slip faulting with $\mathrm{E}-\mathrm{W}$ striking nodal planes. In the area, however, focal mechanisms computed 


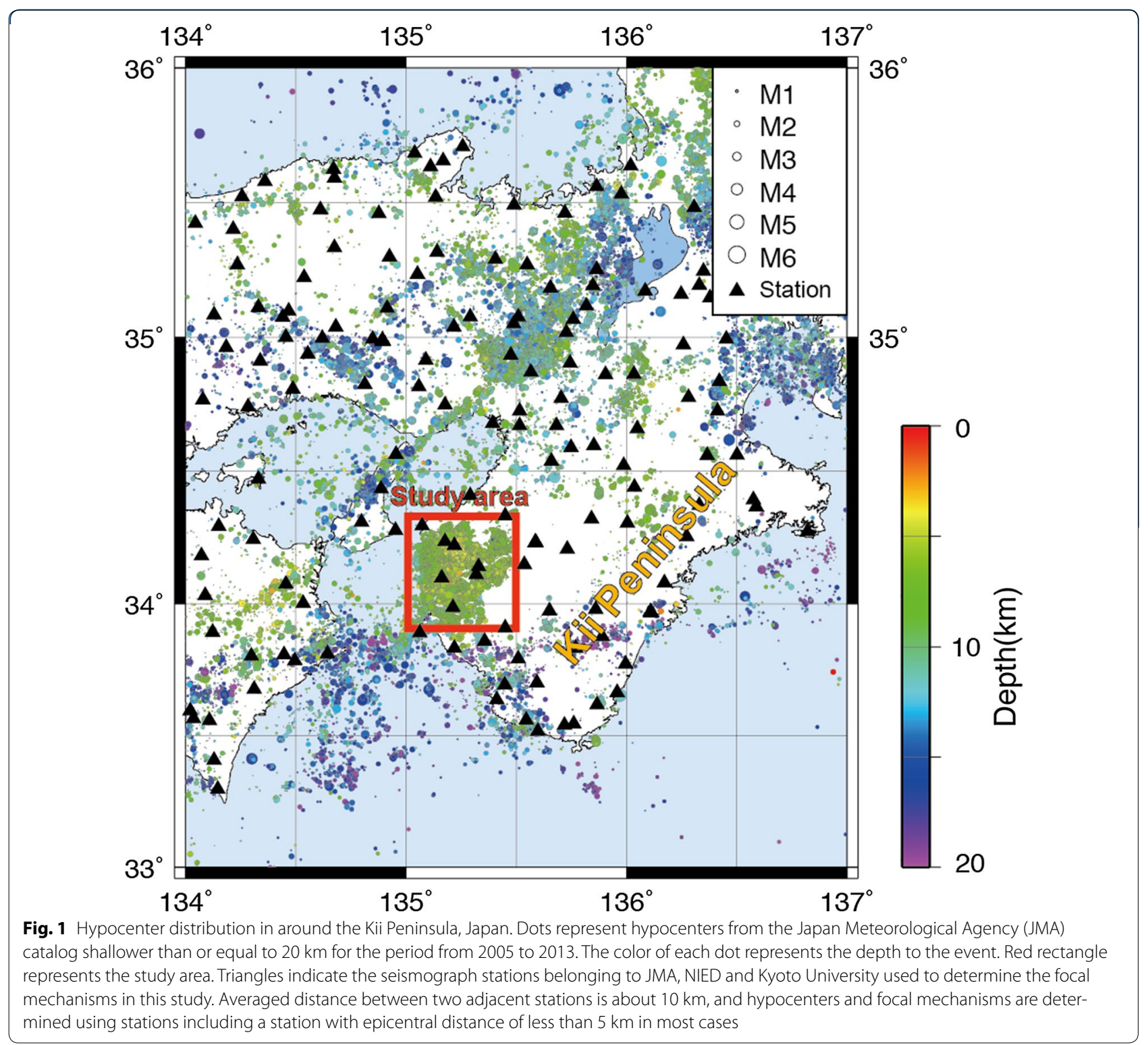

from permanent F-net seismic stations operated by the NIED (National Research Institute for Earth Science and Disaster Resilience, Japan) are dominated by reverse-type focal mechanisms with $\mathrm{N}-\mathrm{S}$ striking nodal planes. This result seems to contradict the fault type and strike expected from linear clusters striking E-W to ENE-WSW. However, the F-net focal mechanism solutions for the study area are limited to earthquakes with $\mathrm{Mw} \geq 3.2$, whereas most of the events in the area are smaller than this. Because of this relatively high magnitude cutoff, it is possible that smaller earthquakes along tectonic lines might strike subparallel to tectonic features. Therefore, investigating the focal mechanisms of smaller events could resolve the contradiction between F-net focal mechanism solutions and earthquake distributions. Moreover, the relationships among focal mechanisms, regional stress, and heterogeneous structure should be investigated in detail, to better understand the local stress regime.

In the present study, we follow a three-step procedure to investigate the relationship between heterogeneous structure and complex seismic activity in the upper 
crust of the Wakayama region. First, we determine the focal mechanisms of micro- and small earthquakes. Second, we estimate the stress field of this area from these focal mechanisms. Finally, we examine the relationship between earthquakes and crustal structure based on geophysical data and geological observations.

\section{Tectonic setting of the study area}

The Wakayama region comprises the northwestern part of the Kii Peninsula, southwestern Japan, where seismic activity is thought to be closely related to geological structure (Huzita 1962; Huzita et al. 1973; Katao and Ando 1996). In this work, we focus primarily on earthquakes in three accretionary complexes: the Sambagawa metamorphic belt, the Chichibu belt, and the Shimanto belt (Fig. 2).
The Sambagawa belt consists of a variety of crystalline schists (e.g., Enami et al. 1994) that formed as an accretionary prism at $\sim 140-130 \mathrm{Ma}$ and were metamorphosed at 120-110 Ma under high-pressure, low-temperature conditions (Aoki et al. 2008). Most of schistosity strikes $\mathrm{N} 110^{\circ} \mathrm{W}$ to $\mathrm{N} 80^{\circ} \mathrm{W}$ and dips $40^{\circ}-90^{\circ}$ to the north (Makimoto et al. 2004). The belt is bounded by the Median Tectonic Line (MTL) to the north and the Aritagawa Tectonic Line (ATL) to the south. The Chichibu and Shimanto belts are located to the south of the Sambagawa metamorphic belt, as shown in Fig. 2. The Chichibu belt is a Jurassic accretionary complex composed of sandstone, mudstone, conglomerate, siliceous shale, chert, limestone, and basalt (e.g., Matsuoka 1992; Wakita 2013). The Shimanto belt is an accretionary prism of Cretaceous to Early Miocene age (e.g., Suzuki and Nakaya

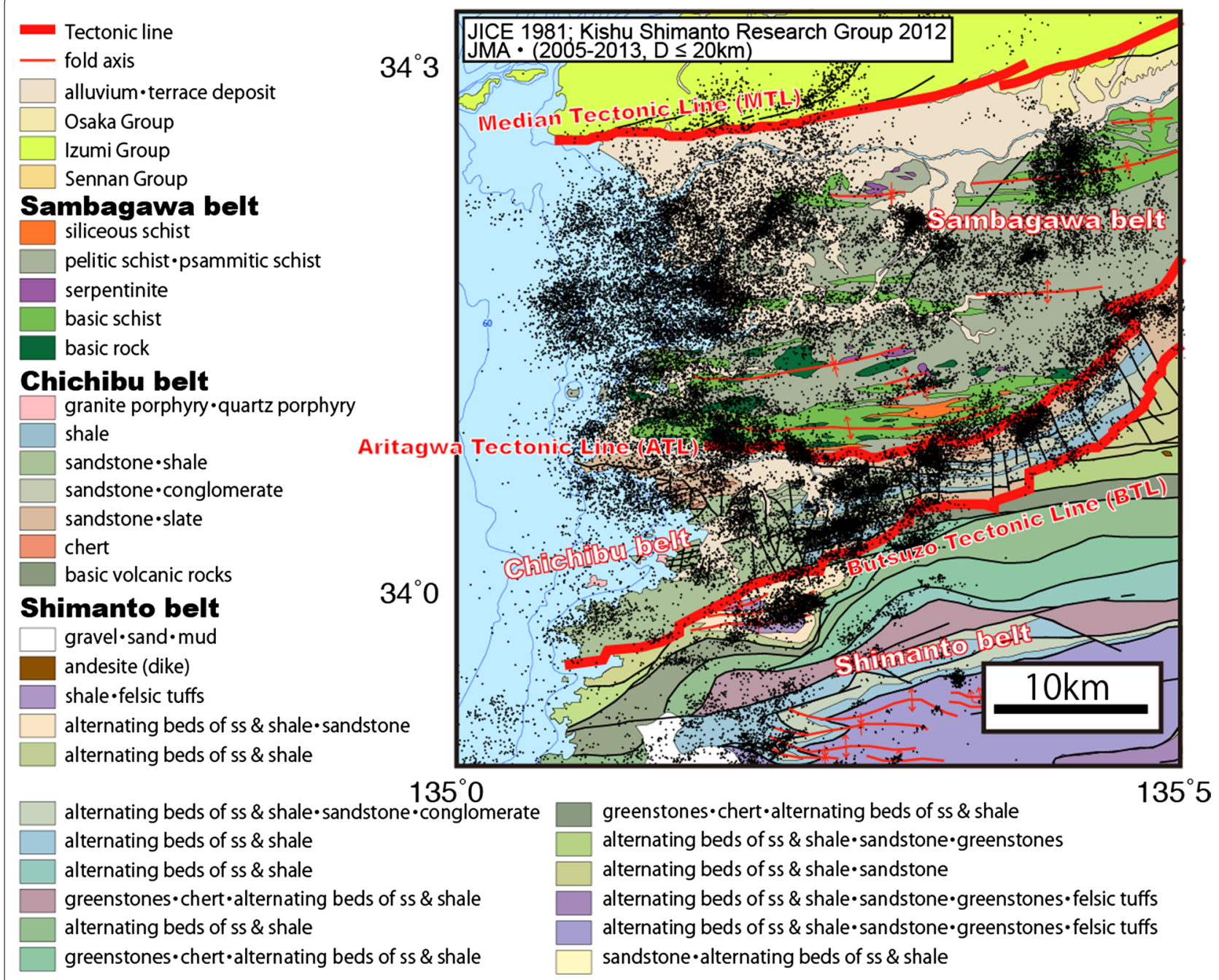

Fig. 2 Geological map and seismic activity in the study area. Geological information is from JICE (1981) and Kishu Shimanto Research Group (2012). Epicenter distribution for earthquakes shallower than or equal to $20 \mathrm{~km}$ in the period from 2005 to 2013 from the JMA catalog is shown by black dots 
2012), composed of turbidites, chert, limestone, and basalt (e.g., Kishu Shimanto Research Group 2012; Wakita 2013). Most of bedding planes in Chichibu and Shimanto belts strike E-W to ENE-WSW and steeply dipping (Yao 2012).

In this area, three significant tectonic lines separate the geologic zones, as shown in Fig. 2. In the Wakayama region, the epicenters of numerous small earthquakes are located mainly in the Sambagawa and Chichibu belts, distributed subparallel to the strike directions and bounded by three tectonic lines: the MTL, the ATL, and the Butsuzo Tectonic Line (BTL).

\section{Determination of focal mechanism solutions}

The waveform data used in this study were obtained from the SATARN system (Ohmi et al. 1999) at the Disaster Prevention Research Institute, Kyoto University, Japan. To determine focal mechanisms and hypocenters, we read P-wave first-motion polarities and onsets from the digital waveform data of each earthquake using the WIN system (Urabe and Tsukada 1992). We attempted to determine focal mechanisms of events from April 2011 to June 2013 with JMA magnitudes greater than 1.1, using the software pick2mec (Katao and Iio 2004; Maeda 1992). This program assigns each focal mechanism a score based on the ratio of consistent polarities to all polarities; e.g., a score value of 1.0 means that all observed initial polarities are consistent with the focal mechanism solution determined by the program. We retained only reliable solutions; i.e., solutions with 10 polarities or more and a score of 0.9 or higher. Moreover, we discarded the data when the nodal planes with the same minimal inconsistent polarities can be drawn in more than ten ways; this quantitative criterion proved very useful for rejecting focal mechanisms that can be classified into two different fault types. If there were plural focal solution candidates with the same best score for a event, the best solution was chosen so that the polarities consistent with that solution were located farthest away from the nodal planes and the polarities inconsistent with the solution were closest to one of the planes. The determined focal mechanism solutions were then classified as "normal," "strikeslip," or "reverse," using the plunge angles of the principal axes (Fig. 3). The classification method is similar to that of Frohlich (1992), but we introduce two grades (A and B) for each fault type: grade $A$ means that the focal mechanism has an axis with a plunge angle $\theta \geq 60^{\circ}$, and grade $\mathrm{B}$ indicates a plunge angle of $45^{\circ} \leq \theta<60^{\circ}$. We classified focal mechanisms satisfying none of these criteria into a group labeled "other types." The velocity structure used in the determination of hypocenters and focal mechanisms are shown in Fig. 4, which was modified from "Uji model" in order to stabilize the hypocenter depths and focal mechanisms of shallow earthquakes.

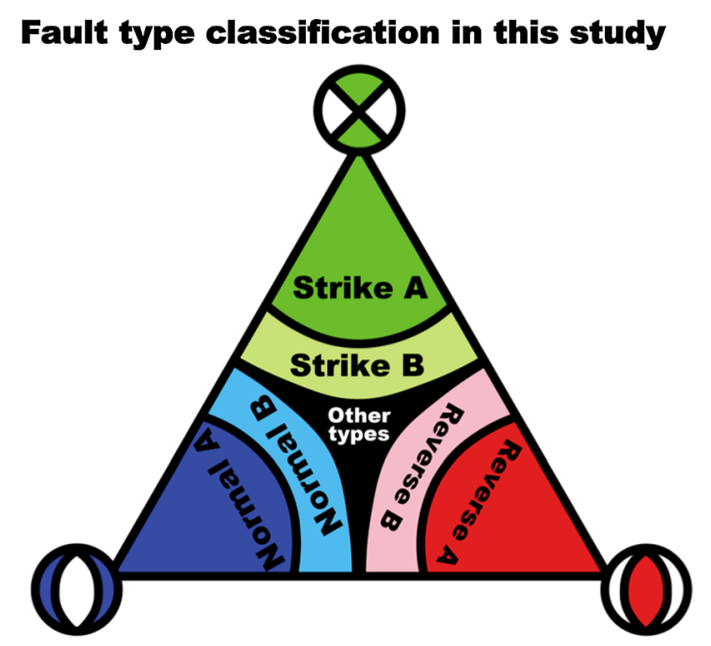

Strilke-slip foult ty/po $A \Rightarrow$ Null axis plunge $\geq 60^{\circ}$

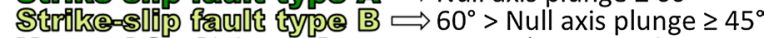

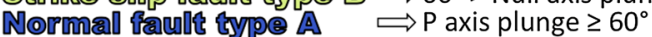

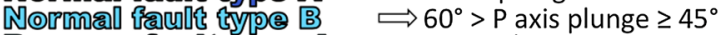

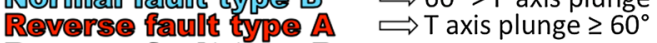

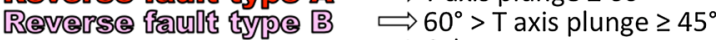
Other types $\Rightarrow$ Other

Fig. 3 Fault type classification in this study. The fault type classification scheme is similar to that of the triangle diagram proposed by Frohlich (1992), but we introduce two grades for each category based on the plunge of the axis. Grade A means that the focal mechanism has an axis with a plunge angle $\theta \geq 60^{\circ}$, and grade $B$ indicates a plunge angle of $45^{\circ} \leq \theta<60^{\circ}$

In this study, we analyzed data after the Tohoku-oki earthquake that occurred on March 11, 2011. Stress change due to the 2011 Tohoku-oki earthquake is estimated to be less than $0.01 \mathrm{MPa}$ in the western Honshu, Japan (Yoshida et al. 2012; Terakawa et al. 2013). Although the seismicity was activated in many places in Japan just after the Tohoku-oki earthquake, such induced activities were limited to eastern Japan except for Shimabara region, Kyushu (Hirose et al. 2011). Therefore, this study area is thought to be not affected by the 2011 Tohoku-oki earthquake, and thus, we used the data after the Tohoku-oki earthquake because it was easy to access newer data than older data in the SATARN system.

We successfully determined reliable focal mechanism solutions for 854 events, or $55 \%$ of all candidate events in this study. The average number of polarity data used in each focal mechanism is 17.1. Examples of the determined focal mechanisms are shown in Fig. 4, and all the focal mechanisms classified as normal fault types are shown in Additional file 1: Figures A1 and A2. Note that the focal mechanisms are constrained well due to the good station coverage. The distribution of the focal mechanisms determined in this study is shown in Fig. 5b. All focal mechanisms in the F-net catalog during the 


\section{a}

\section{Strike-slip fault}

120714.040140

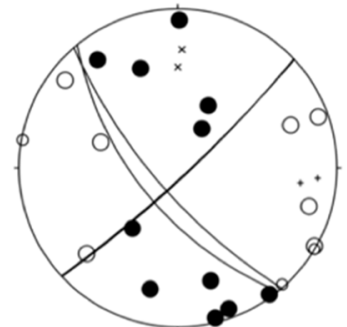

$M=1.8 \mathrm{sc}=1.000$

130507.191712

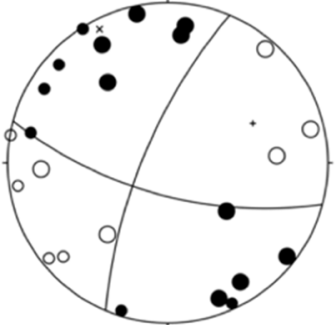

$M=2.0 \mathrm{sc}=1.000$
Reverse fault

121225.113304

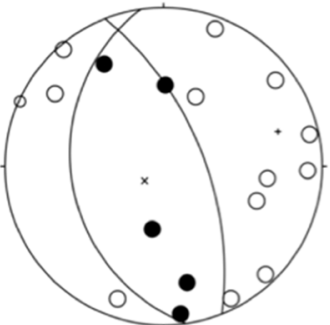

$M=2.8 \mathrm{sc}=1.000$

130112.055300

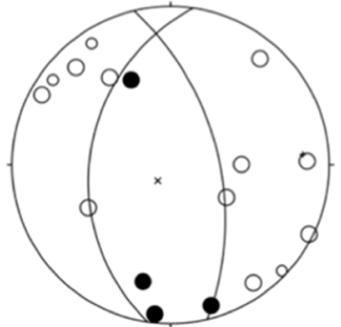

$M=3.0 \mathrm{sc}=1.000$
Normal fault

110814.041828

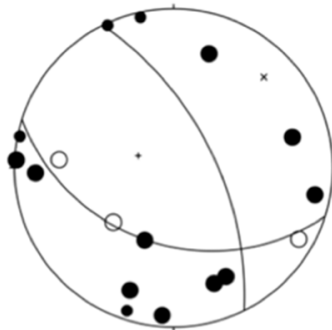

$M=1.6$ sc $=1.000$

130219.073656

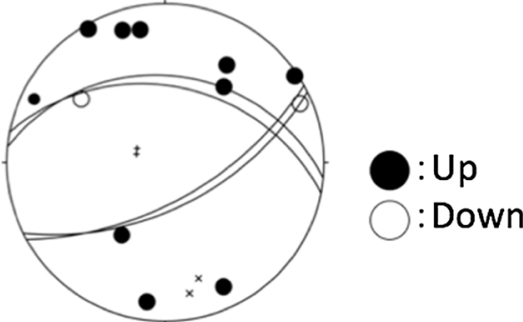

$M=1.5 \mathrm{sc}=1.000$

b

Uji model

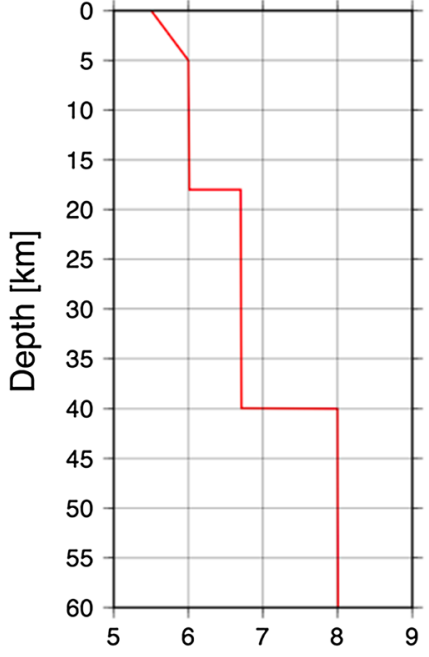

P-wave Velocity $[\mathrm{km} / \mathrm{s}]$

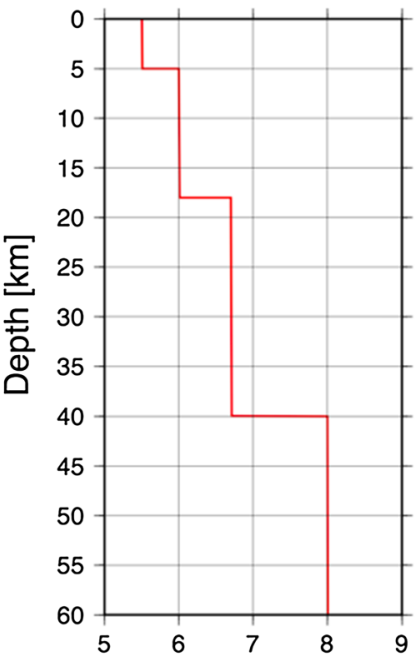

$\mathrm{P}$-wave Velocity [ $\mathrm{km} / \mathrm{s}]$

Fig. 4 Examples of focal mechanisms determined and P-wave velocity structure used in this study. a The focal mechanisms are projected onto the upper hemisphere using the stereo projection (Wulff net). Solid and open circles respectively indicate the upward (compressional) and downward (dilatational) first motions. The occurrence time is shown at the top of each focal solution, and the magnitude and score are shown at the bottom where "score" means a ratio of the data consistent to the obtained solution to the total data. b The left panel represents the P-wave velocity structure used in this study and the right panel shows the structure used in the hypocenter determination for the central Kinki district by the Disaster Prevention Research Institute, Kyoto University

study period are classified as reverse faulting (Fig. 5a). On the other hand, reverse-faulting-type events in our study account for only $60 \%$ of total events, and $31 \%$ of our earthquakes are classified as strike-slip or normal faulting (Fig. 6). The figure also shows the ratios of fault types for events with $M \geq 2.5$ and $M<2.5$, revealing that reverse 


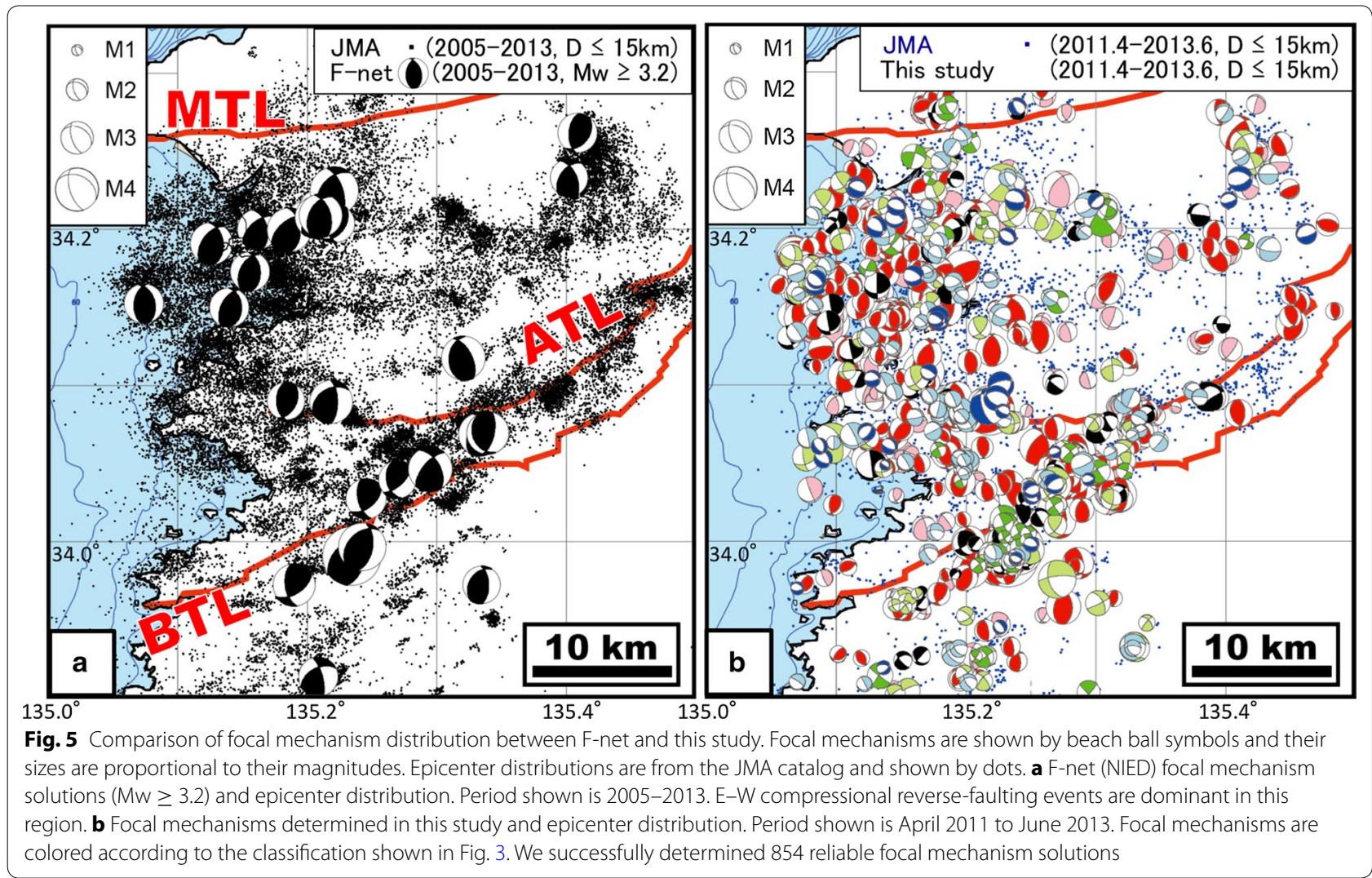

faulting is predominant among larger events, but other faulting styles are more important for smaller events. We searched the entire F-net catalog from 1997 and found a very few events with $M \geq 3.2$ and a faulting style other than reverse before 2005. In total, only two strike-slip events are listed in the F-net catalog from January 1997 to June 2013; the other 46 events (i.e., 96\%) are reverse faulting.

Figure 7 shows the distributions of the $\mathrm{P}$ - and $\mathrm{T}$-axes of our focal mechanisms. Most P-axes are aligned E-W to WNW-ESE, while the T-axes are aligned N-S to NNE-SSW. Hypocenters are mainly distributed at depths of 3-6 km in the northwestern part of the study area, $5-10 \mathrm{~km}$ in the south, and $10-12 \mathrm{~km}$ in the northeast.

The median and average of hypocenter depths for each fault type are listed in Table 1. The standard error and the 95\% confidence interval of each average are also shown. First, we carried out Welch's $t$ test for unequal variances to assess the statistical significance of the differences in depth distributions. Results show that the differences in hypocentral depth distributions between normal and strike-slip events are significant at the $1 \%$ level $(p=0.0073)$. For other combinations, however, the differences are not so significant $(p=0.1425$ for normal and reverse types, and $p=0.0483$ for reverse and strike-slip types). Unlike Student's $t$ test, Welch's $t$ test does not assume the same variances in two populations, but it assumes that the populations follow normal distributions. Unfortunately, the distributions seem not to follow normal distributions as shown in Fig. 8a. Therefore, we also carried out a Wilcoxon rank sum test and reevaluation of confidence intervals using a bootstrap method to assess the statistical significance of the differences in depths.

Wilcoxon rank sum test can be used even if the populations cannot be assumed to be normally distributed. Results show that the differences in hypocentral depth distributions for different faulting styles are significant at the 5\% level ( $p=0.0222$ for normal and reverse types, and $p=0.0169$ for reverse and strike-slip types). In particular, the depth differences between normal and strike-slip events are significant even at the $1 \%$ level $(p=0.0003)$. We next carried out a bootstrap resampling 1000 times and plotted the averages and medians for respective bootstrap samples in Fig. 8b. Bootstrap estimations of $95 \%$ confidence intervals for the averages and medians are also shown. The confidence intervals for the averages are consistent with the values shown in Table 1 . The depth differences of the medians between the different fault types are clearer than the averages, which is 


\section{Proportion of fault type}

This study (854 solutions)

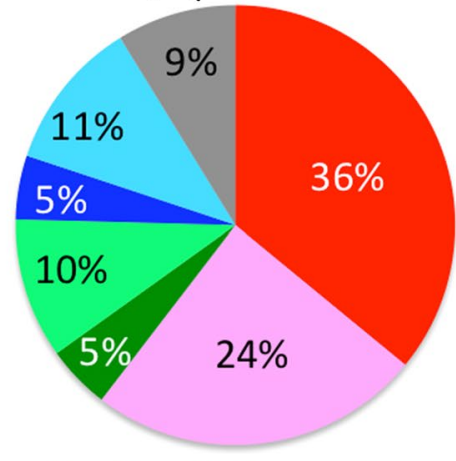

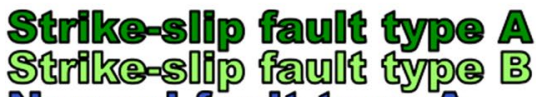

Normal f์ult tyy A

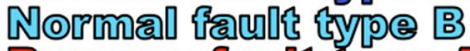

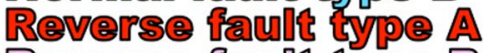

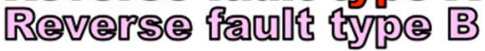
Other types
$M \geq 2.5$ (72 solutions)
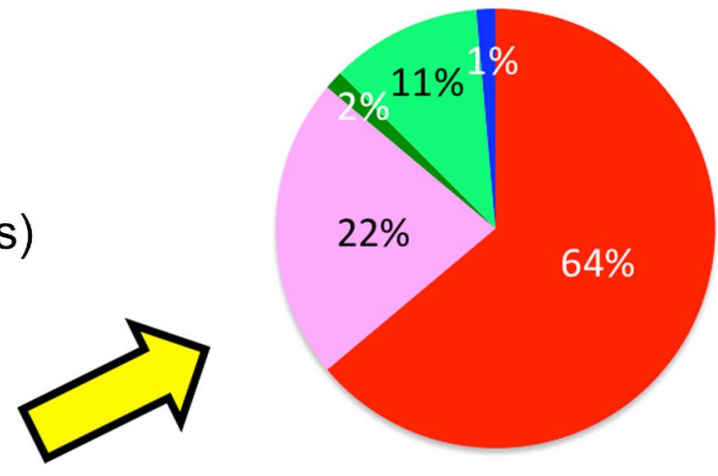

$M<2.5$ (782 solutions)
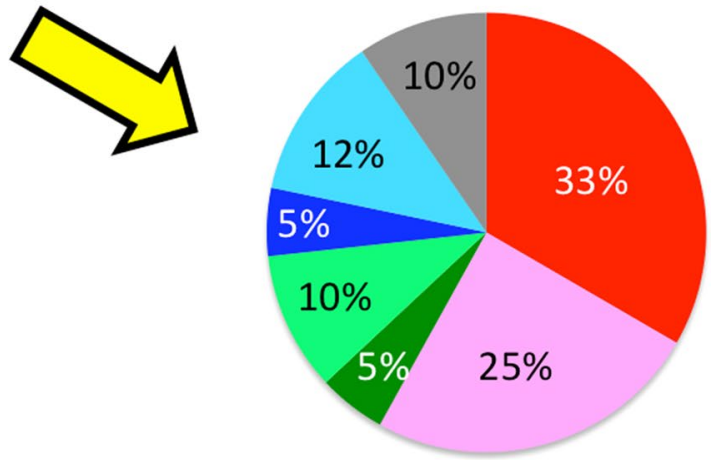

Fig. 6 Pie charts showing the proportion of each fault type. The distributions of events with $M \geq 2.5$ and $M<2.5$ are shown at right. See caption of Fig. 3 and text for the explanation of grades $A$ and $B$

also consistent with the Wilcoxon rank sum test because both the test and the medians are calculated from the rank orders and are robust against outliers. Therefore, we judge that the difference in the depth distributions is meaningful.

Our results indicate that most focal mechanisms are categorized into three groups, and the depths in each group are distinct: (1) N-S tensional events driven by normal faulting occur mainly in the shallower part of the area; (2) E-W compressional-type events, driven by reverse faulting, occur mainly in the middle of the depth range; and (3) $\mathrm{N}-\mathrm{S}$ tensional and $\mathrm{E}-\mathrm{W}$ compressional events (i.e. strike-slip-type) occur mainly at the greatest depths (Fig. 8).

\section{Estimation of the stress field}

As described above, we found that the depth distribution of hypocenters depends on the faulting style. We next examine whether such variations are due to depthdependent changes in the stress field.

We estimated the stress field of the study area using our focal mechanisms and a stress inversion method proposed by Michael $(1984,1987)$. This technique makes the following assumptions: (1) the direction of tangential traction on the fault plane is parallel to the slip direction, (2) the stress field is uniform in the analysis area during the time window studied, (3) the magnitude of the tangential traction is the same on all fault planes considered, and (4) earthquakes occur along pre-existing weak planes having various strikes and dips. The method can estimate the orientations of stress axes and the stress ratio $R=\left(\sigma_{1}-\sigma_{2}\right) /\left(\sigma_{1}-\sigma_{3}\right)$, where $\sigma_{1}, \sigma_{2}$, and $\sigma_{3}$ are the maximum, intermediate, and minimum principal compressive stresses, respectively.

The results of the stress inversion are shown in Fig. 9a. The stress field is estimated to be E-W compressional reverse faulting if we use whole focal mechanism data in the study area, in agreement with previous studies (e.g., Terakawa and Matsu'ura 2010). On the other hand, the stress field estimated in 1- and 3-km depth intervals is shown in Fig. 9b-h. These results indicate that the stress field varies with depth: the shallower part of the stress field shows $\mathrm{N}-\mathrm{S}$ tension and $\mathrm{E}-\mathrm{W}$ compression, consistent with strike-slip faulting, while the deeper part shows 


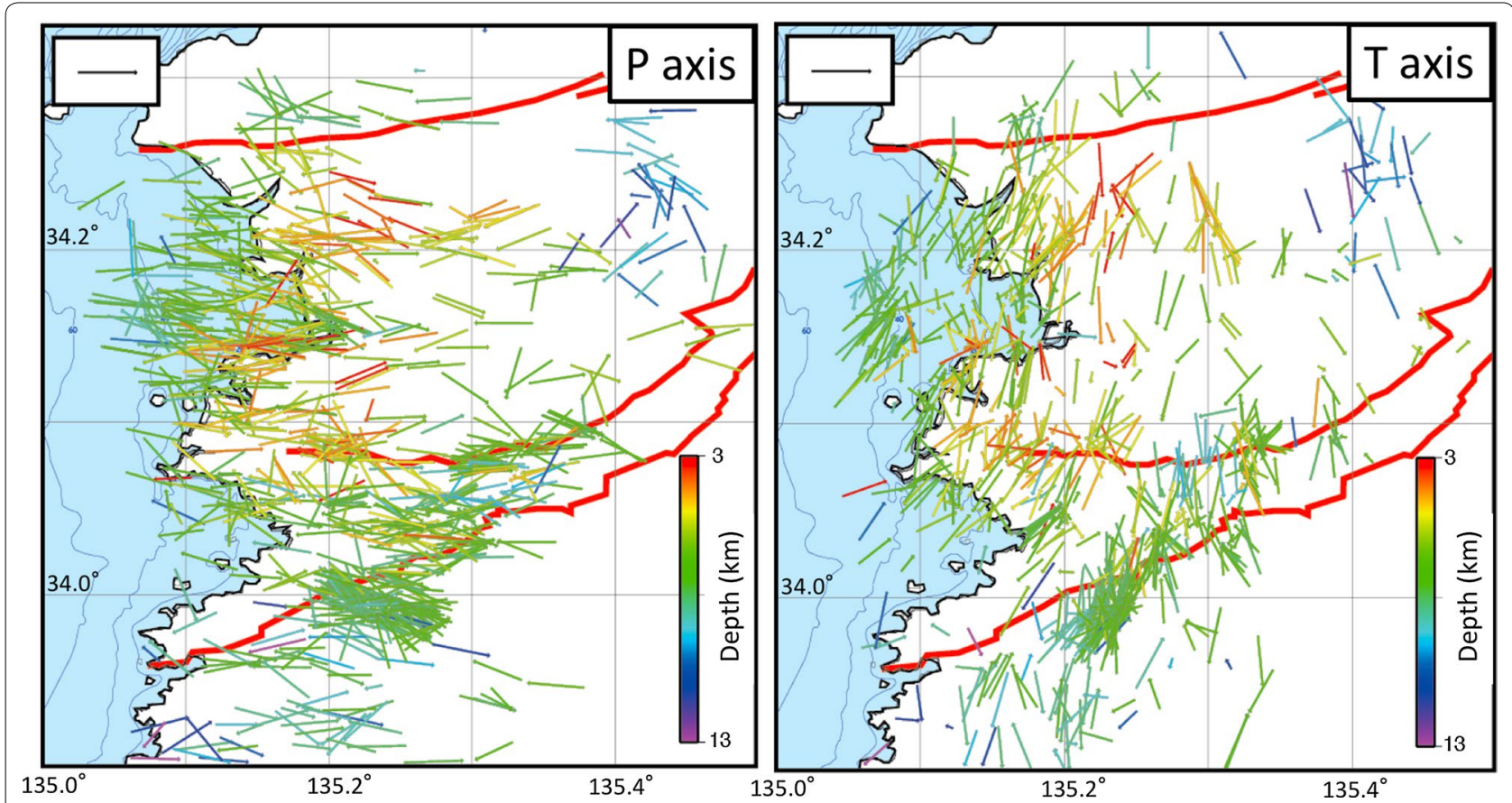

Fig. 7 P-axis (left) and T-axis (right) distributions. Starting point and color of each arrow show the epicenter and depth of the hypocenter determined in this study, respectively. Principal axes are plotted using an orthographic projection, and the direction and length of each arrow represent the orientation and inclination of the axis, respectively. The upper left of each figure shows the scale when the inclination is $0^{\circ}$

Table 1 Median and average values of hypocentral depths of each faulting style

\begin{tabular}{llll}
\hline & Normal (135) & Reverse (516) & Strike (128) \\
\hline Median $(\mathrm{km})$ & 6.22 & 6.76 & 7.14 \\
Average $(\mathrm{km})$ & 6.45 & 6.70 & 7.00 \\
Standard error $(\mathrm{km})$ & 0.16 & 0.07 & 1.03 \\
$\begin{array}{l}\text { 95\% confidence interval } \\
(\mathrm{km})\end{array}$ & $6.14-6.76$ & $6.56-6.84$ & $6.74-7.26$ \\
\hline
\end{tabular}

\#Numbers in parentheses indicate the number of events of each faulting style used in the calculations. "Standard error" and "95\% confidence interval" are for each average depth

E-W compression, corresponding to reverse faulting. The obtained stress ratio $R$ of close to 1.0 means that the magnitude of $\sigma_{2}$ is almost the same as $\sigma_{3}$, which is consistent with the observation that both reverse and strikeslip events have P-axes oriented E-W.

\section{Discussion}

Many of the focal mechanisms (especially, normal fault and strike-slip fault) we computed have nodal planes oriented subparallel to geologic boundaries (Fig. 5b), which was not clear in the F-net data, although some earthquakes close to the BTL seem to have catalog nodal planes subparallel to tectonic lines (Fig. 5a). This result indicates that the micro- and small earthquakes might be influenced by heterogeneous structure in the upper crust. We also found that the dominant faulting style varies with depth. In the following subsections, we discuss the relationship between focal mechanisms, stress regime, and heterogeneous structure in detail.

(1) Cause and mechanisms of complex microseismic activity.

In the Wakayama region, heat flow data and seismic velocity structure indicate the presence of hot fluid beneath the hypocenters (e.g., Kato et al. 2010, 2014; Matsumoto 2007; Omuralieva et al. 2012; Tanaka et al. 2004; Yoshida et al. 2011). Nakajima and Hasegawa (2007) pointed out that high seismicity in this study area is probably related to locally concentrated fluids. High seismicity attributed to fluids is also pointed out elsewhere (e.g., Kosuga 2014; Terakawa et al. 2013). Due to the influence of fluid, pore pressure is considered high enough to weaken the faults in this study area.

The crustal temperature is estimated to be $300-400{ }^{\circ} \mathrm{C}$ at the lower boundary of the seismogenic layer (e.g., Ito 1990 ; Sibson 1982) and $100-150{ }^{\circ} \mathrm{C}$ at the upper boundary (Ito 2008). The seismogenic layer in the study area is much shallower than in other areas of southwestern 


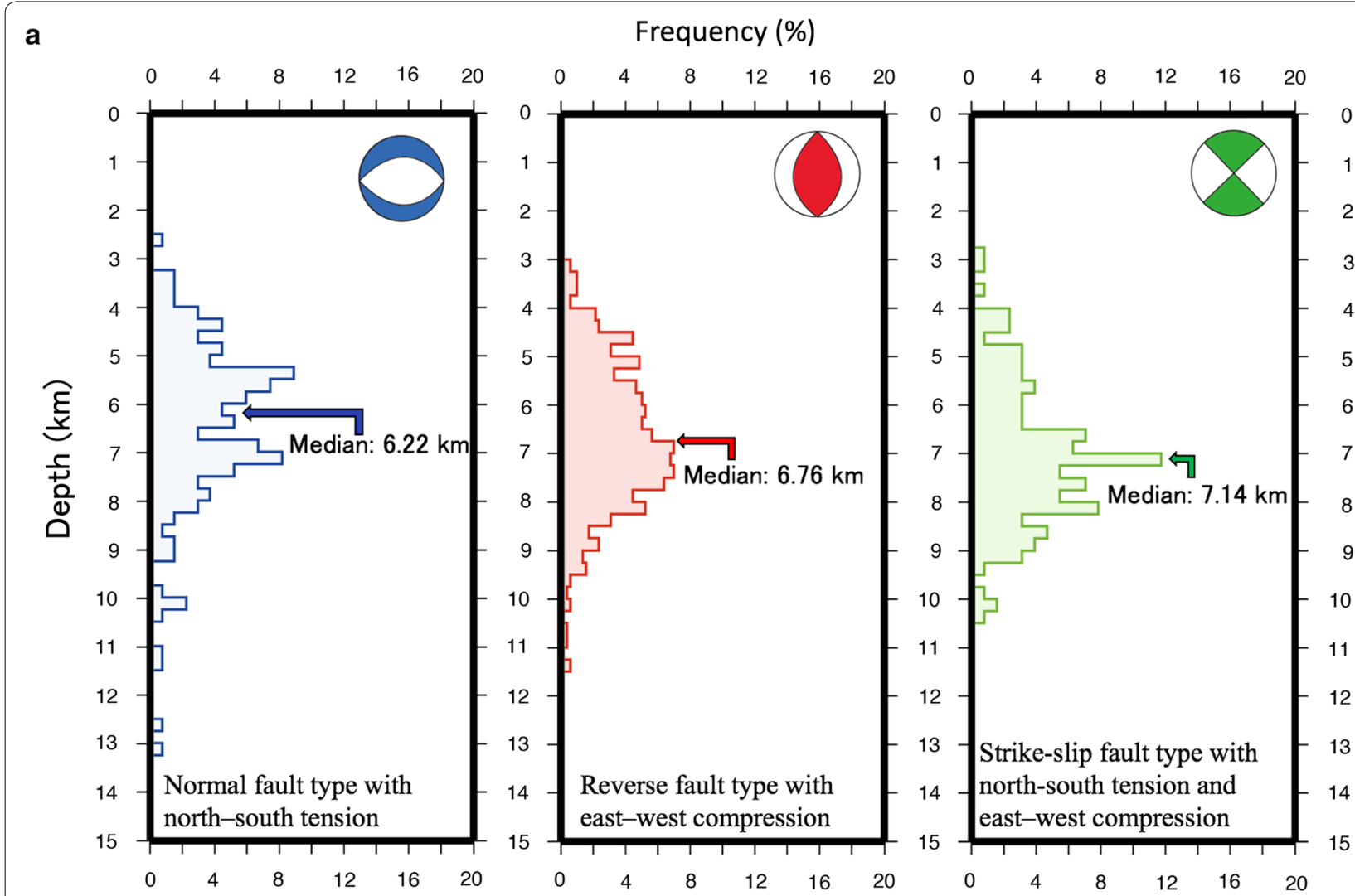

b

Histogram_Mean

Histogram_Median
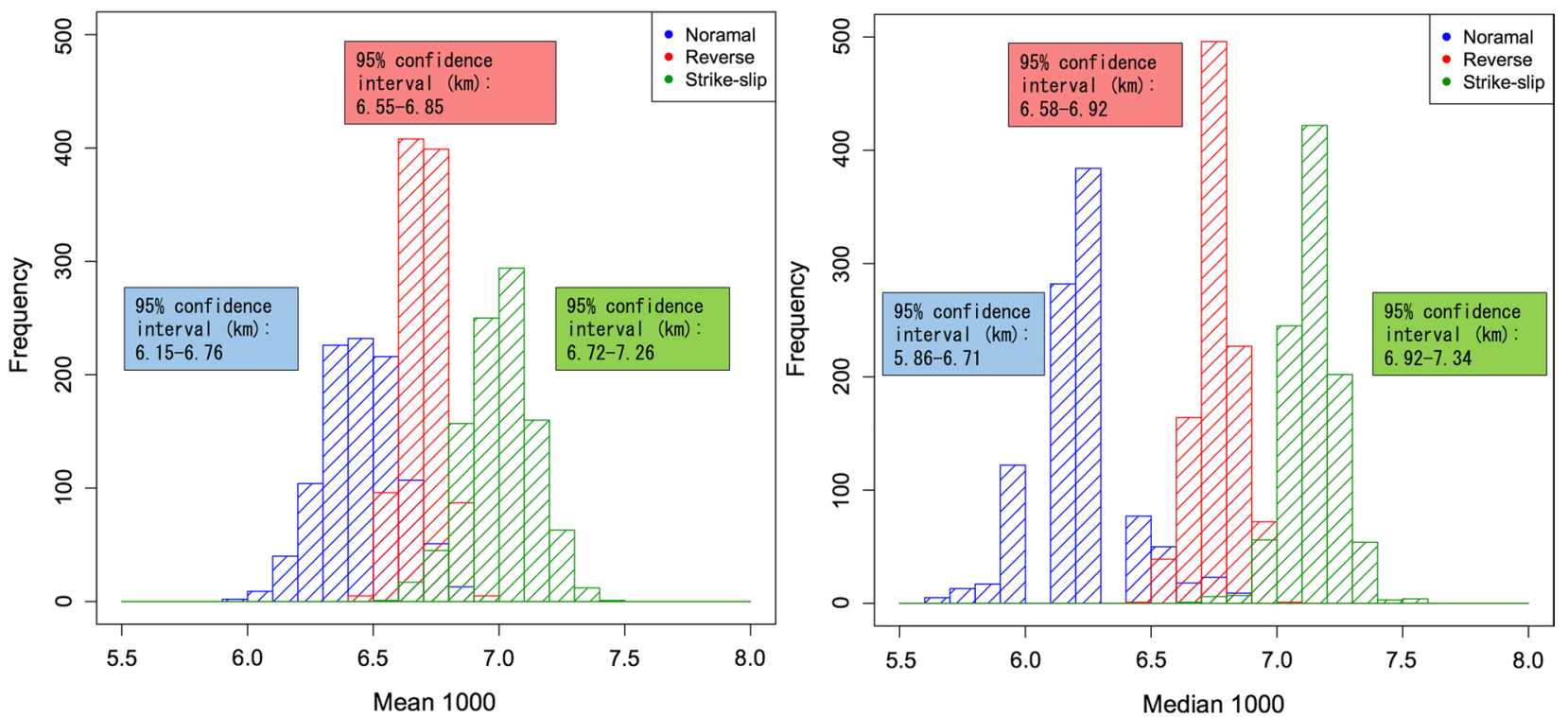

Fig. 8 Depth distribution of each faulting type. a Histograms of the depths for respective faulting types. Blue, red, and green histograms correspond to normal, reverse, and strike-slip focal mechanisms, respectively. Median depths for respective mechanisms are indicated by arrows. b Bootstrap sample distributions of the averages (left) and medians (right) of the depths for respective faulting types. Confidence intervals of $95 \%$ are also shown in the boxes. Bootstrap resamplings were carried out 1000 times. The lack of the medians for $6.01-6.10$ and $6.31-6.40 \mathrm{~km}$ ranges is due to the accidental lacks of the original data in these ranges. In this study area, most of the focal mechanisms are categorized into these three groups, and the predominant depth differs among the groups: (1) N-S tensional normal fault-type events mainly occur in the shallower part, (2) E-W compressional reverse-fault-type events dominate at intermediate depths, and (3) N-S tensional and E-W compressional strike-slip-fault-type events mainly occur at the greatest depths 
Japan, which is consistent with the estimated heat flow distribution (Omuralieva et al. 2012; Tanaka et al. 2004).

The stress field in the study area varies with depth, as described in the previous section and shown in Fig. 9. The main cause of these depth variations is probably thermal stress, which implies a similar regime to the thermal stress model for the intraslab earthquakes (Goto et al. 1985; Hamaguchi et al. 1983; Manea et al. 2006). If a heat source is really located in the crust as pointed out by Yoshida et al. (2011), the crust immediately above it warms and expands (Fig. 10a). The surrounding areas, however, are still cold, despite being contiguous with the hotter region. Thus, the surrounding areas resist expansion, and eventually horizontal compressive stress acts on the warm region, while tensional stress dominates the colder region (Fig. 10b).

Let us roughly calculate the effect of the thermal stress. First, we calculate a typical crustal stress assuming an Andersonian stress state (having a vertical principal stress) and no tectonic stress. The vertical stress $\sigma_{z}$ is expected to be the same as a gravitational stress

$$
\sigma_{z}^{g}=\rho g z,
$$

where $\rho$ is the density, $g$ is the gravitational acceleration, and $z$ is the depth. If the density is homogeneous, horizontal strain is expected to be zero (uniaxial strain).
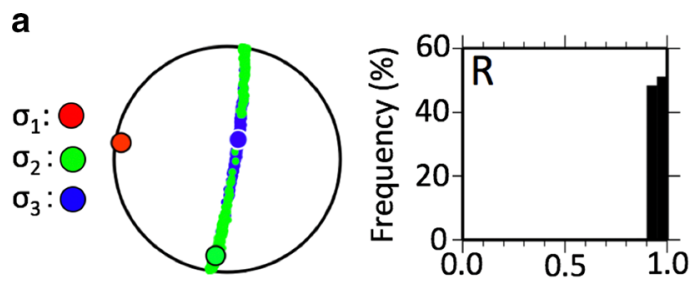

$4 \mathrm{~km}(\mathrm{n}=99) 5 \mathrm{~km}(\mathrm{n}=167) 6 \mathrm{~km}(\mathrm{n}=189) 7 \mathrm{~km}(\mathrm{n}=215) 8 \mathrm{~km}(\mathrm{n}=105)$

b
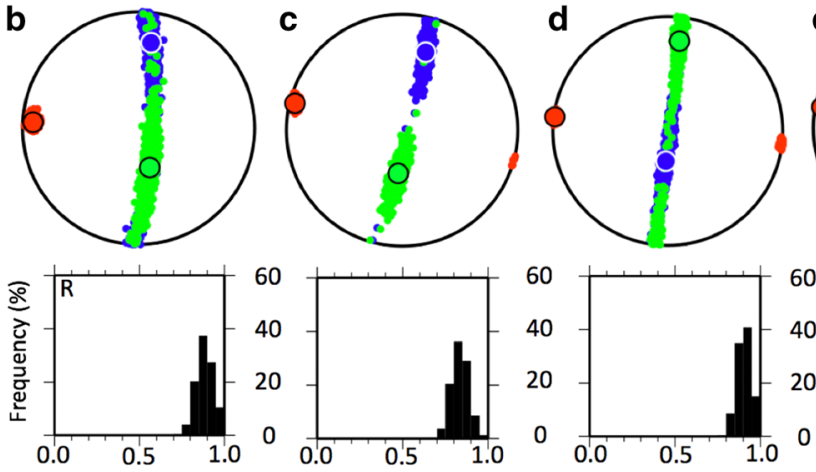

Shallower

Strike-slip fault type stress

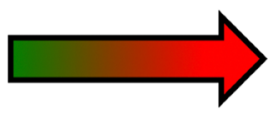

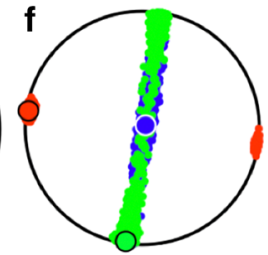
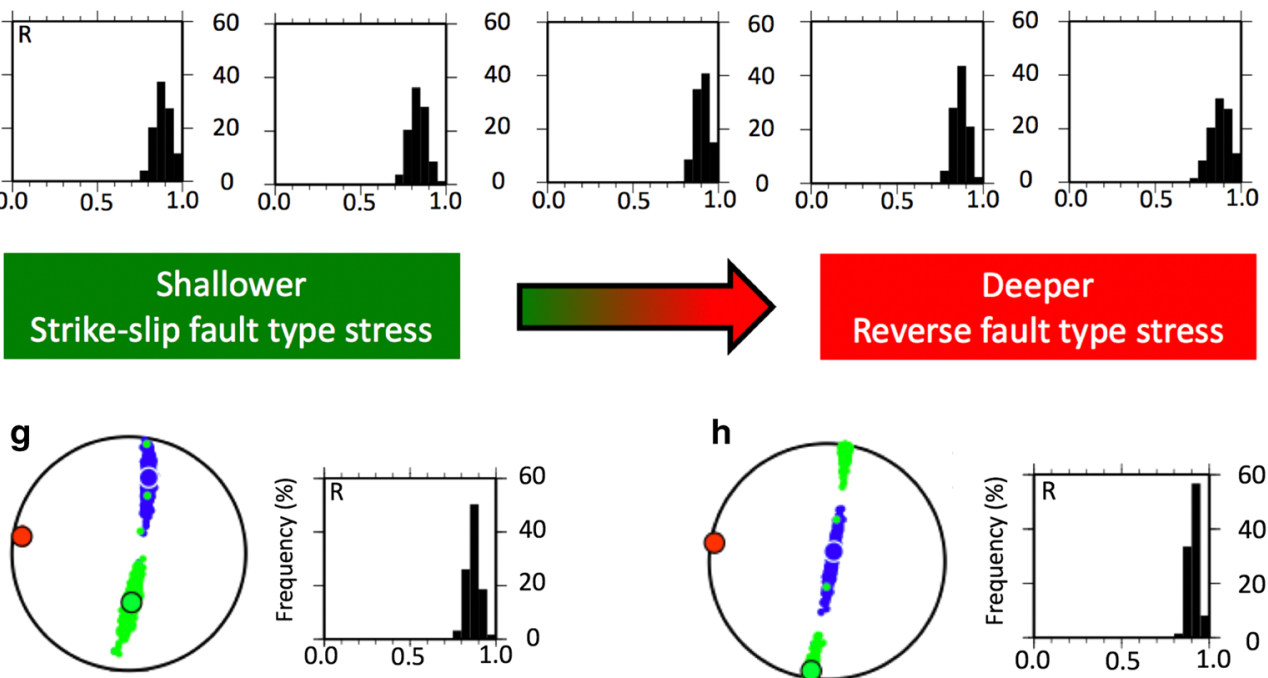

$3.0 \leq$ Depth $(\mathrm{km}) \leq 6.0$
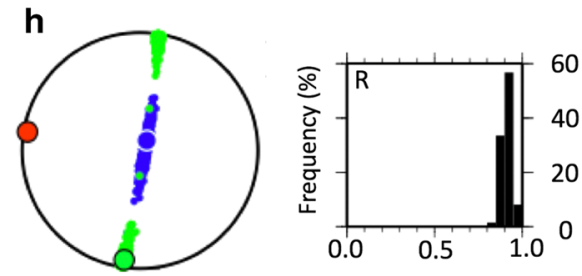

\section{$6.0 \leq$ Depth $(\mathrm{km}) \leq 9.0$}

Fig. 9 Stress fields estimated in this study. Stress axis orientations and $R$-values estimated for the entire study area (a), in 1-km depth slices (b-f) and in 3-km depth slices $(\mathbf{g}, \mathbf{h})$ are shown. Principal stress axis orientations and $95 \%$ confidence intervals are projected onto lower hemisphere equalarea projections. Red, green, and blue circles correspond to the $\sigma_{1}, \sigma_{2}$, and $\sigma_{3}$ axes, respectively. Background color of "shallower strike-slip fault-type" and "deeper reverse fault-type stress" indicates fault type; the same color scheme is used throughout this study 


\section{a Unconstrained case}

$2 \mathrm{~km}$
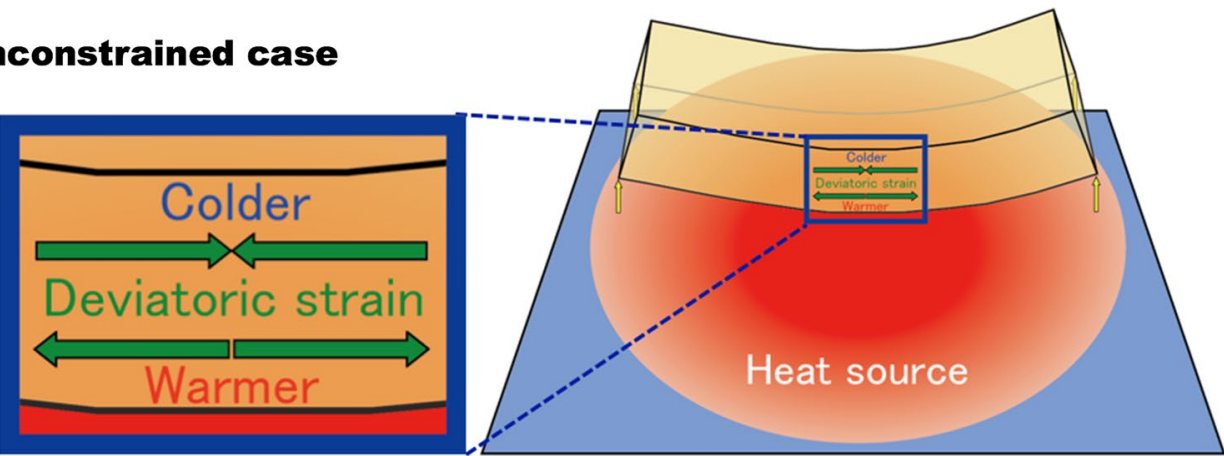

\section{b Constrained case}

$2 \mathrm{~km}$
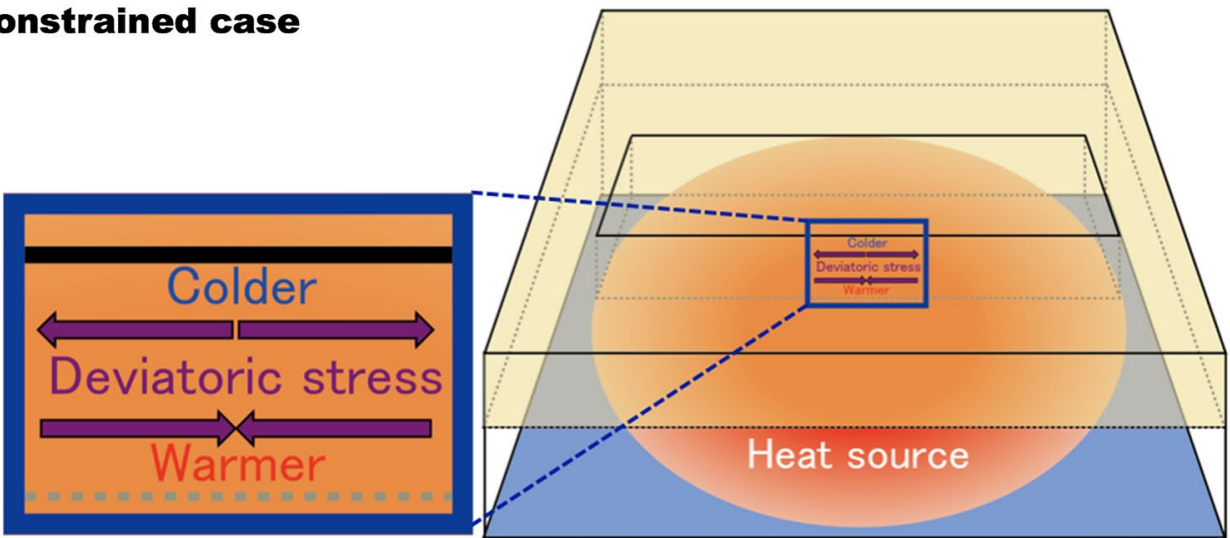

Fig. 10 Schematic depth distribution of stress due to a deep heat source. Close-up of the central vertical plane (blue rectangle) is shown to the left of each figure. a If a rock block is located above a heat source, and the block can be freely deformed, the bottom half of the block will expand due to heating. In this case, horizontal deviatoric strain is contraction in the shallower part and dilatation in the lower part as indicated by green arrows. Note that this strain is not the elastic strain but the thermal one causing no stress change. $\mathbf{b}$ In the crust, however, the block cannot be freely deformed, but becomes locked at each end. Horizontal deviatoric stress becomes compressional in the bottom half and tensional in the top half as indicated by purple arrows. Note that the vertical deviatoric strain and stress are not plotted in the figure, for the sake of simplicity. Here we presume that hot water or partial melt is acting as a heat source as proposed by Yoshida et al. (2011) and Kato et al. (2014)

Then, horizontal stress due to the vertical gravitational stress is calculated as

$$
\sigma_{x}^{g}=\sigma_{y}^{g}=\frac{v}{1-v} \sigma_{z}^{g},
$$

where $v$ is the Poisson's ratio. If the temperature depends on the depth only, the crust will expand only vertically and again horizontal strain is expected to be zero. In this case, the horizontal thermal stress is calculated as

$$
\sigma_{x}^{T}=\sigma_{y}^{T}=\frac{\alpha E \Delta T}{1-v},
$$

where $\alpha$ is the coefficient of thermal expansion, $E$ is the Young's modulus, and $\Delta T$ is the temperature contrast. We use here a sign convention that the compressional stress is expressed as a positive value. The typical geothermal gradient at non-volcanic regions in Japan is about $30 \mathrm{~K} / \mathrm{km}$ (Tanaka et al. 2004), which means $\Delta T=300 \mathrm{~K}$ between $10 \mathrm{~km}$ depth and the ground surface. Assuming $\rho=3 \times 10^{3} \mathrm{~kg} / \mathrm{m}^{3}, \quad g=9.8 \mathrm{~m} / \mathrm{s}^{2}$, $z=10 \mathrm{~km}, v=0.25, \alpha=1 \times 10^{-5} \mathrm{~K}^{-1}$, and $E=50 \mathrm{GPa}$, we obtain $\sigma_{z}^{g}=294 \mathrm{MPa}, \sigma_{x}^{g}=\sigma_{y}^{g}=98 \mathrm{MPa}$, and $\sigma_{x}^{T}=\sigma_{y}^{T}=200 \mathrm{MPa}$ at $10 \mathrm{~km}$ depth. This means $\sigma_{z}=\sigma_{z}^{g}=294 \mathrm{MPa}$, and $\sigma_{x}=\sigma_{y}=\sigma_{x}^{g}+\sigma_{x}^{T}=298 \mathrm{MPa}$ at $10 \mathrm{~km}$ depth. Thus, a lithostatic stress state can be achieved in regions with a typical geothermal gradient.

In the Wakayama region, the geothermal gradient is at least 1.5 times larger than the typical value (Matsumoto 2007; Tanaka et al. 2004), which means horizontal compressional stress can be larger than the average (e.g., $100 \mathrm{MPa}$ larger at $10 \mathrm{~km}$ depth) when there is no horizontal strain. In this case, however, the crust is expected to locally expand horizontally. The amount of the horizontal expansion depends on the boundary conditions which are not known. If we assume the compressional stress averaged over the top $10 \mathrm{~km}$ contributes to the expansion (i.e., the horizontal stress at $5 \mathrm{~km}$ depth is 
balanced with the surroundings), horizontal stress is expected to be $50 \mathrm{MPa}$ smaller than the vertical stress at $0 \mathrm{~km}$ depth (horizontal tension) and $50 \mathrm{MPa}$ larger at $10 \mathrm{~km}$ depth (horizontal compression). We must take the $\mathrm{E}-\mathrm{W}$ compressional tectonic stress and effect of inhomogeneous structure also into account, but it is hard to evaluate them quantitatively. Even if large E-W compressional tectonic stress is applied, $\mathrm{N}-\mathrm{S}$ component of tensional stress mentioned above is expected to remain. Recent studies indicate that the differential stresses in seismically active regions are of the order of $10 \mathrm{MPa}$ (e.g., Hardebeck and Hauksson 2001; Yoshida et al. 2014). Therefore, we conclude the thermal stress caused by the local heat source can generate shallow N-S tensional normal fault-type earthquakes in the Wakayama region.

The normal fault-type events, however, are fewer than reverse fault-type events as shown in Fig. 6. Earthquakes hardly occur at the shallowest depths $(z \leq 2 \mathrm{~km})$ even if the horizontal tensional stress is expected to be largest there according to the thermal stress model, because the normal stresses on the faults are too small and the temperature is too low. Therefore, the tensional stress field just beneath the surface is not likely to resolve in a stress inversion that uses focal mechanisms, even if the stress model proposed here is correct. The stress fields that produce the shallow strike-slip faulting and deep reverse faulting, as shown in Fig. 9 can thus be explained by this model without resolving stress in the shallowest layer.

Our model predicts that the shallow tensional region and deep compressional region should be clearly separated while the separation is not clear in the observation as shown in Figs. 8 and 9. We think this difference is due to small-scale heterogeneities in the stress caused by the earthquakes. An earthquake can disturb the surrounding stress orientation considerably when the differential stress is small as pointed out by many studies (e.g., Hardebeck and Hauksson 2001; Yoshida et al. 2014). Moreover, if the elastic constants are inhomogeneous, the stress field can be also inhomogeneous to some extent. Since the Wakayama region is seismically very active and the geological structure is very complex as shown in Fig. 2, the small-scale heterogeneity in the stress is expected to be high. This also indicates that the pore pressure in the Wakayama region should be very high because otherwise it is impossible to generate earthquakes in such complicated stress distribution.

A depth-dependent change in the stress field due to a heat source is likely to occur in areas where magma exists underground, such as calderas (e.g., Sadikin et al. 2007). Although this study area is not currently an active volcanic zone, the ${ }^{3} \mathrm{He} /{ }^{4} \mathrm{He}$ ratios are anomalously high (Matsumoto et al. 2003; Morikawa et al. 2016; Sano and Wakita 1985; Umeda et al. 2006). High ${ }^{3} \mathrm{He} /{ }^{4} \mathrm{He}$ ratios are normally seen in the mantle. If a high ${ }^{3} \mathrm{He} /{ }^{4} \mathrm{He}$ ratio is observed at the surface, this suggests that mantle material has ascended from depth. Low-velocity regions in the lower crust and upper mantle revealed by tomographic studies also support the idea (e.g., Kato et al. 2014; Nakajima and Hasegawa 2007). Kato et al. (2014) proposed that the mantle wedge and lower crust beneath the nonvolcanic seismic swarm area are being hydrated by fluids released from dehydration of subducting oceanic crust. Nakajima and Hasegawa (2007) interpreted that a large low-velocity region in the upper mantle beneath the Kii Peninsula might represent a hydrated upwelling flow.

The high heat flow, inferred underground fluid, and high ${ }^{3} \mathrm{He} /{ }^{4} \mathrm{He}$ ratio are similar to features of volcanic areas. Thus, it might be useful to compare the stress fields revealed in this study with those of active volcanic zones, to better understand the seismic activity in this area. In particular, comparisons with volcanic zones in northeastern Honshu, Japan, should be carried out in future studies to verify the model proposed here because reverse-faulting events are also predominant in northeastern Honshu, according to the F-net catalog.

In this study, we do not discuss the temporal nor horizontal change in the stress, but we consider the vertical variation only because the number of data is not enough. There might be a very subtle temporal change, but we think the temporal change as well as horizontal variation of the stress should be left for the future study.

(2) Nodal planes and fault types controlled by the stress field and geological structure.

The present results show that the stress field in the shallower part of Wakayama region is dominated by N-S tension and E-W compression, generating strike-slip faulting, while the deeper part is an E-W compressional reverse-fault regime (Fig. 9b-h). Nevertheless, strikeslip events tend to occur in the deepest part, as shown in Fig. 8.

Earthquake clusters are linearly distributed along the Chichibu belt and Shimanto belt, as shown in Fig. 2. Strike-slip earthquakes are densest around the BTL, which forms the boundary between the two belts (Fig. 11); the hypocentral depths are deeper there than in the northern part of the study area, as shown in Fig. 7. Geologically mapped vertical faults striking ENE-WSW are predominant in the Chichibu and Shimanto belts (Fig. 11), and strike oblique to the direction of maximum principal compressive stress, which is oriented $\mathrm{E}-\mathrm{W}$ in a broad region around the study area (Terakawa and Matsu'ura 2010). These vertical faults are probably weaker than intact rocks; thus, they can generate strike-slip earthquakes even if the stress regime is more 


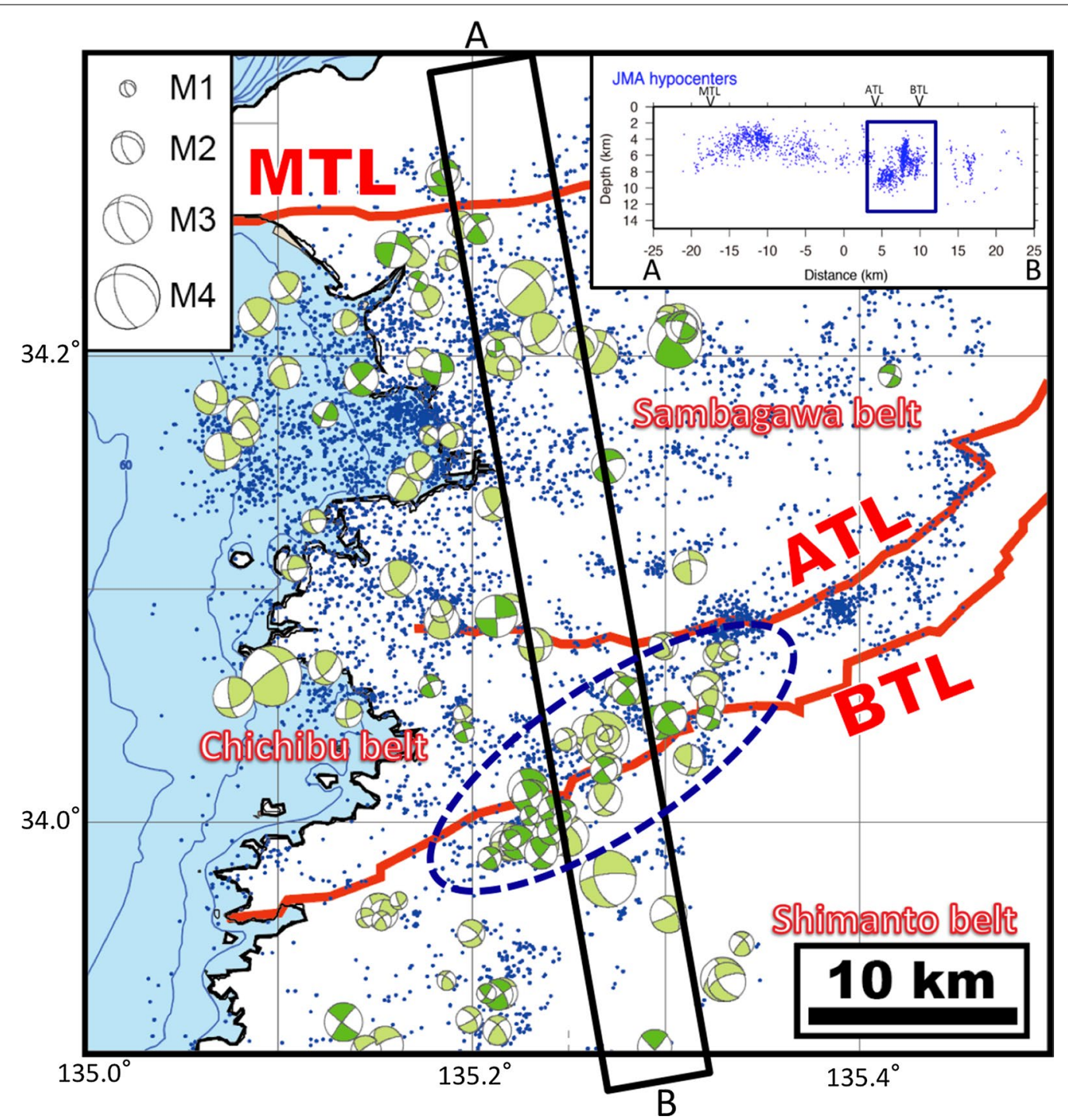

Fig. 11 Strike-slip fault-type focal mechanism distribution in the study area. Almost the same as the right figure in Fig. 5 but normal fault-type and reverse fault-type events are omitted. The events of strike-slip faulting are concentrated close to the Butsuzo Tectonic Line (BTL), indicated by the blue dashed ellipse. The inserted diagram at upper right is a cross section of hypocenter distributions from the JMA catalog for the earthquakes in the long black rectangle in the map. The hypocenters in the blue rectangle in the cross section are aligned vertically, suggesting vertical faults

conducive to reverse faulting. For example, in 1996 at Onikobe in northeastern Japan, the northwestern wall of a caldera slipped as a fault, generating a Mj 5.7 earthquake where $\mathrm{E}-\mathrm{W}$ compressional stress was predominant (Umino et al. 1998). Therefore, the apparent contradiction between the predominant strike-slip focal mechanisms in Fig. 8 and the reverse-faulting stress regime at depth in Fig. 9 can be explained by the existence of vertical weak planes.

The same logic can be applied to the shallow normal fault; if the shallow stress regime is E-W compressional and $\mathrm{N}-\mathrm{S}$ tensional strike-slip fault-type, $\mathrm{N}-\mathrm{S}$ tensional normal fault-type events can occur in places with weak planes striking E-W and dipping shallow. Note that if stress regime is of $\mathrm{E}-\mathrm{W}$ compressional reverse fault type regardless of the depth, $\mathrm{N}-\mathrm{S}$ tensional normal fault-type events cannot occur even if such weak planes exist.

The results mentioned above are summarized in Fig. 12, which shows that thermal stress caused by deep heat source and E-W compressional regional tectonic stress are responsible to the stress in this study area. The observed focal mechanisms are controlled by weak planes under the stress regime shown in Fig. 12. The influence of geological structure has been discussed in several previous studies (e.g., Kanamori and Tsumura 1971; Katao and Ando 1996; Umino et al. 1998), but the details of how 


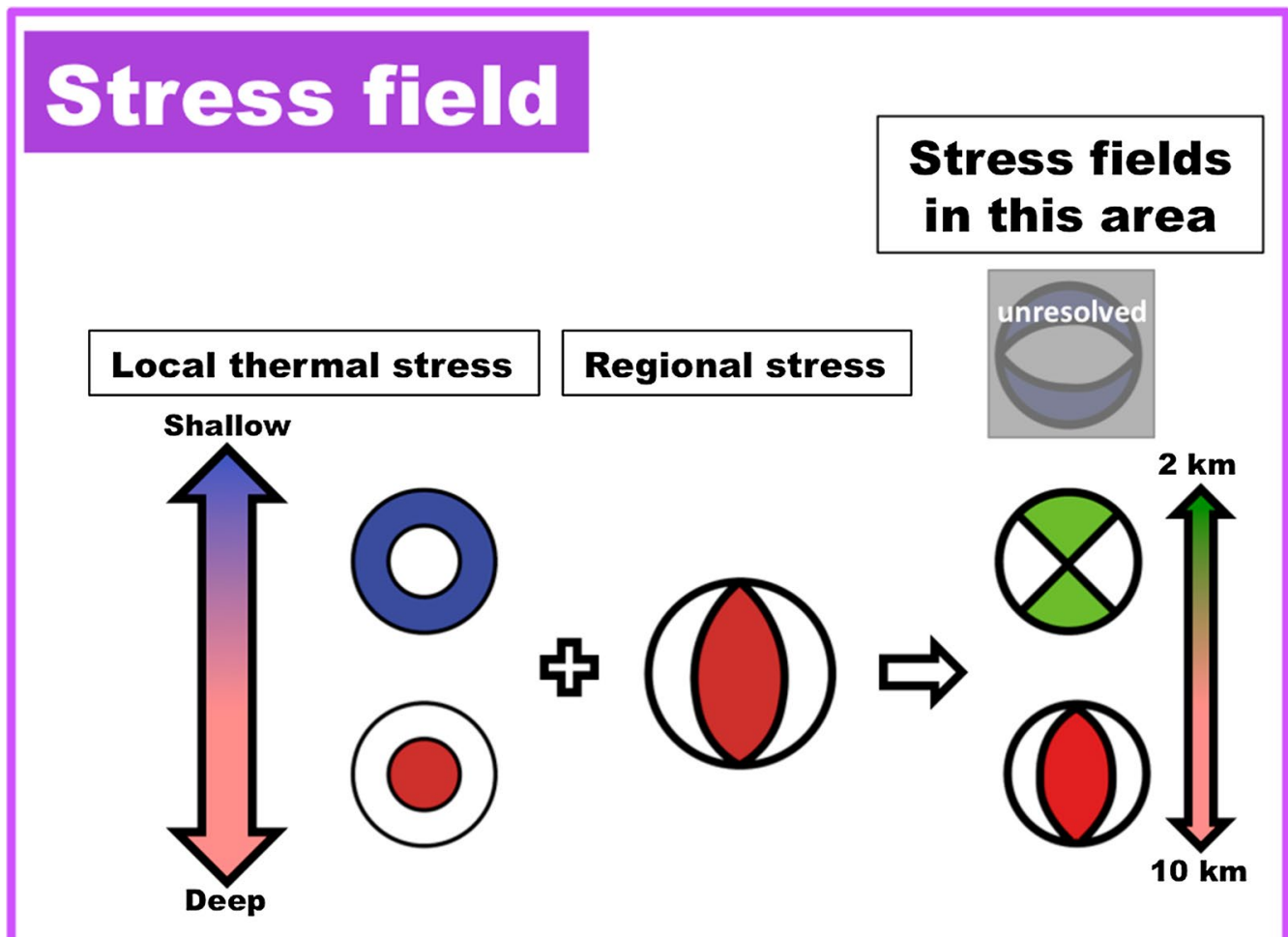

Fig. 12 Conceptual diagram of the stress field proposed in this study. The stress field in this study area can be explained by a combination of local thermal stress and regional tectonic stress. Focal mechanisms are controlled by weak planes such as geological faults under the stress regime shown here. Earthquakes hardly occur at the shallowest depths $(z \leq 2 \mathrm{~km})$ because the normal stresses on the faults are too small. Therefore, the tensional stress field just beneath the surface is not likely to resolve in a stress inversion that uses focal mechanisms. For this reason, we labeled "unresolved"for the expected stress field in the shallowest part

it controls earthquake generation remain unclear. The shapes of existing weak planes and the characteristics of the structures responsible (e.g., rock type, density) should be investigated in detail in other areas, to verify whether the model proposed in this study can explain the complicated earthquake activity in the Wakayama region.

\section{Conclusions}

To explore how heterogeneous crustal structure controls seismic activity, we examined the spatial relationship between seismic activity and heterogeneous structure in the Wakayama region, northwestern Kii Peninsula, Japan. Focal mechanisms of small to microearthquakes determined in this study mainly fall into three groups, and the depth ranges of the respective groups show statistically significant differences: (1) normal faulting events with $\mathrm{N}-\mathrm{S}$-oriented $\mathrm{T}$-axes mainly occur at shallow depths; (2) reverse faulting events with $\mathrm{E}-\mathrm{W}$-oriented P-axes dominate at intermediate depths; and (3) strike-slip faulting events with $\mathrm{N}-\mathrm{S}$-oriented T-axes and $\mathrm{E}-\mathrm{W}$-oriented $\mathrm{P}$-axes are mainly seen at greater depths. The results of stress inversions also indicate that the stress field varies with depth: shallower depths are characterized by $\mathrm{N}-\mathrm{S}$ tension and $\mathrm{E}-\mathrm{W}$ compression, while greater depths are subjected to $\mathrm{E}-\mathrm{W}$ compression and vertical tension. A stress ratio $R$ close to 1.0 indicates that $\sigma_{2}$ is similar in magnitude to $\sigma_{3}$, consistent with the observation that most local reverse and strike-slip events have P-axes oriented E-W. The depth-dependent stress variations can be explained by thermal stress from a deep heat source in the lower crust. The contradiction between the predominantly strike-slip focal mechanisms and a stress regime at depth most conducive to reverse faulting is probably due to the existence of vertical geological faults. To elucidate the generation mechanism of inland earthquakes, it is necessary to further investigate deep structure as well as microearthquake activity, the stress field, the presence of fluids, and the effects of heat sources.

\section{Additional file}

Additional file 1. Figure A1 Focal mechanism solutions of normal fault type classified as grade $\mathrm{A}$ 


\section{Abbreviations}

ATL: Aritagawa Tectonic Line; BTL: Butsuzo Tectonic Line; JMA: Japan Meteorological Agency; MTL: Median Tectonic Line; NIED: National Research Institute for Earth Science and Disaster Resilience.

\section{Authors' contributions}

Data analysis and manuscript preparation were mainly carried out by SM. ST and TM directed the study in an earlier stage and a later stage, respectively. HK and KY lead the waveform data analysis and stress tensor inversion, respectively. All authors read and approved the final manuscript.

\section{Author details}

${ }^{1}$ Graduate School of Science, Tohoku University, 6-6 Aza-Aoba, Aramaki, Aoba-ku, Sendai 980-8578, Japan. ${ }^{2}$ International Research Institute of Disaster Science, Tohoku University, 468-1 Aza-Aoba, Aramaki, Aoba-ku, Sendai 980-0845, Japan. ${ }^{3}$ Research Center for Earthquake Prediction, Disaster Prevention Research Institute, Kyoto University, Gokasho, Uji, Kyoto 611-0011, Japan.

\section{Acknowledgements}

We thank T. Yoshida, T. Kubota, T. Shiina, and R. Takagi at Tohoku University and E. Tani at Kyoto University for fruitful discussions. The comments from the Lead Guest Editor Y. lio and two anonymous reviewers are very helpful in revising the manuscript. We used the unified earthquake catalog of the Japan Meteorological Agency (JMA) and the F-net focal mechanism catalog of the National Research Institute for Earth Science and Disaster Resilience. We also used a seamless digital geological map of Japan compiled by the Geological Survey of Japan at the National Institute of Advanced Industrial Science and Technology. The figures in this paper were prepared using the Generic Mapping Tools (GMT) software package (Wessel and Smith 1998).

\section{Competing interests}

The authors declare that they have no competing interests.

\section{Availability of data and materials}

The datasets analyzed in the current study available from the corresponding author on reasonable request.

\section{Consent for publication}

Not applicable.

\section{Ethics approval and consent to participate}

Not applicable.

\section{Funding}

This research was supported by Sasakawa Scientific Research Grant from the Japan Science Society (No. 26-218) and by JSPS KAKENHI Grant Number JP26109002

\section{Publisher's Note}

Springer Nature remains neutral with regard to jurisdictional claims in published maps and institutional affiliations.

Received: 25 March 2017 Accepted: 24 January 2018

Published online: 07 February 2018

\section{References}

Aoki K, Itaya T, Shibuya T, Masago H, Kon Y, Terabayashi M, Kaneko Y, Kawai T, Maruyama S (2008) The youngest blueschist belt in SW Japan: implication for the exhumation of the Cretaceous Sanbagawa highP/T metamorphic belt. J Metamorph Geol 26:583-602. https://doi. org/10.1111/j.1525-1314.2008.00777.x

Enami M, Wallis SR, Banno Y (1994) Paragenesis of sodic pyroxene-bearing quartz schist: implications for the P-T history of the Sanbagawa belt. Contrib Mineral Petrol 116:182-198. https://doi.org/10.1007/BF00310699

Frohlich C (1992) Triangle diagrams: ternary graphs to display similarity and diversity of earthquake focal mechanisms. Phys Earth Planet Inter 75:193-198. https://doi.org/10.1016/0031-9201(92)90130-N
Goto K, Hamaguchi H, Suzuki Z (1985) Earthquake generating stresses in a descending slab. Tectonophysics 112:111-128. https://doi. org/10.1016/0040-1951(85)90175-1

Hamaguchi H, Goto K, Suzuki Z (1983) Double-planed structure of intermediate-depth seismic zone and thermal stress in the descending plate. J Phys Earth 31:329-347. https://doi.org/10.4294/jpe1952.31.329

Hardebeck JL, Hauksson E (2001) Crustal stress field in southern California and its implications for fault mechanics. J Geophys Res 106:21859-21882. https://doi.org/10.1029/2001JB000292

Hirose F, Miyaoka K, Hayashimoto N, Yamazaki T, Nakamura M (2011) Outline of the 2011 off the Pacific coast of Tohoku Earthquake (Mw 9.0)_Seismicity: foreshocks, mainshock, aftershocks, and induced activity-. Earth Planets Space 63:513-518. https://doi.org/10.5047/eps.2011.05.019

Huzita K (1962) Tectonic development of the median zone (Setouti) of Southwest Japan, since the Miocene with special reference to the characteristic structure of central Kinki area. J Geosci Osaka City Univ 6:103-144

Huzita K, Kishimoto Y, Shiono K (1973) Neotectonics and seismicity in the Kinki area, southwest Japan. J Geosci Osaka City Univ 16:93-124

Ito K (1990) Regional variations of the cutoff depth of seismicity in the crust and their relation to heat flow and large inland-earthquakes. J Phys Earth 38:223-250. https://doi.org/10.14989/doctor.r7263

Ito K (2008) Source processes of inland earthquakes and heterogeneous structure revealed from large earthquakes. Ann Disas Prev Res Inst Kyoto Univ 51A:95-110 (in Japanese)

Japan Institute of Country-ology and Engineering (1981) Engineering geological map of Kinki district, scale 1:200,000

Kanamori H, Tsumura K (1971) Spatial distribution of earthquakes in the Kii peninsula, Japan, south of the Median Tectonic Line. Tectonophysics 12:327-342. https://doi.org/10.1016/0040-1951(71)90020-5

Katao H, Ando M (1996) Seismicity before and after the Hyogoken-Nanbu earthquake. Kagaku 66:78-85 (in Japanese)

Katao H, lio Y (2004) Focal mechanisms of microearthquakes in the Tamba Plateau. Ann Disas Prev Res Inst Kyoto Univ 47B:674-678 (in Japanese)

Katao H, Kubo A, Yamashina T, Matsushima T, Aizawa K, Sakai S, Shibutani T, Nakao S, Yoshimura R, Kiuchi R, Miura T, lio Y (2014) Focal mechanisms of aftershocks for the M6.3 Awaji Island earthquake on Apr. 13, 2013. Ann Disas Prev Res Inst Kyoto Univ 57B:80-84 (in Japanese)

Kato A, Sakai S, lidaka T, Iwasaki T, Hirata N (2010) Non-volcanic seismic swarms triggered by circulating fluids and pressure fluctuations above a solidified diorite intrusion. Geophys Res Lett 37:L15302. https:/doi. org/10.1029/2010GL043887

Kato A, Saiga A, Takeda T, Iwasaki T, Matsuzawa T (2014) Non-volcanic seismic swarm and fluid transportation driven by subduction of the Philippine Sea slab beneath the Kii Peninsula, Japan. Earth Planets Space 66(1):86. https://doi.org/10.1186/1880-5981-66-86

Kishu Shimanto Research Group (2012) Geologic map of the Shimanto belt (Shimanto accretionary prism) in the Kii Peninsula, scale 1:200,000

Kosuga M (2014) Seismic activity near the Moriyoshi-zan volcano in Akita Prefecture, northeastern Japan: implications for geofluid migration and a midcrustal geofluid reservoir. Earth Planets Space 66:77. https://doi. org/10.1186/1880-5981-66-77

Lee WHK, Stewart SW (1981) Principles and applications of microearthquake networks. In: Adv geophys supplement no 2. Academic Press, New York, p 293

Maeda N (1992) A method of determining focal mechanisms and quantifying the uncertainty of the determined focal mechanisms for microearthquakes. Bull Seismol Soc Am 82:2410-2429

Makimoto H, Miyata T, Mizuno K, Sangawa A, Geological Survey of Japan, AIST (ed.) (2004) Geology of the Kokawa district. Quadrangle Series, 1:50,000, Kyoto (11) No 81, p 16 (in Japanese)

Manea V, Manea M, Kostoglodov V, Sewell G (2006) Intraslab seismicity and thermal stress in the subducted Cocos plate beneath central Mexico. Tectonophysics 420:389-408. https://doi.org/10.1016/j.tecto.2006.03.029

Matsumoto T (2007) Terrestrial heat flow distribution in Japan area based on the temperature logging in the borehole of NIED Hi-net. Abstract T23A-1217, presented at 2007 Fall Meeting, AGU, San Francisco, California, 10-14 Dec

Matsumoto T, Kawabata T, Matsuda J, Yamamoto K, Mimura K $(2003){ }^{3} \mathrm{He} /{ }^{4} \mathrm{He}$ ratios in well gases in the Kinki district, SW Japan: surface appearance of slab-derived fluids in a non-volcanic area in Kii Peninsula. Earth Planet Sci Lett 216:221-230. https://doi.org/10.1016/S0012-821X(03)00479-5 
Matsumoto S, Katao H, lio Y (2015) Determining changes in the state of stress associated with an earthquake via combined focal mechanism and moment tensor analysis: application to the 2013 Awaji Island earthquake Japan. Tectonophysics 649:58-67. https://doi.org/10.1016/j. tecto.2015.02.023

Matsuoka A (1992) Jurassic and Lower Cretaceous tectonic evolution of the Southern Chichibu terrane, southwest Japan. Palaeogeogr Palaeocl 96:71-88. https://doi.org/10.1016/0031-0182(92)90060-I

Michael AJ (1984) Determination of stress from slip data; faults and folds. $J$ Geophys Res 89:11517-11526. https://doi.org/10.1029/JB089iB13p11517

Michael AJ (1987) Use of focal mechanisms to determine stress: a control study. J Geophys Res 92:357-368. https://doi.org/10.1029/ JB092iB01 p00357

Morikawa N, Kazahaya K, Takahashi M, Inamura A, Takahashi HA, Yasuhara M, Ohwada M, Sato T, Nakama A, Handa H, Sumino H, Nagao K (2016) Widespread distribution of ascending fluids transporting mantle helium in the fore-arc region and their upwelling processes: noble gas and major element composition of deep groundwater in the Kii Peninsula, southwest Japan. Geochim Cosmochim Acta. https://doi.org/10.1016/j. gca.2016.03.017

Nakajima J, Hasegawa A (2007) Tomographic evidence for the mantle upwelling beneath southwestern Japan and its implications for arc magmatism. Earth Planet Sci Lett 254:90-105. https://doi.org/10.1016/j. epsl.2006.11.024

Ohmi S, Watanabe K, Hirano N, Nakagawa A, Takeuchi F, Katao H, Takeuchi H, Asada T, Koizumi M, Ito K, Wada H, Shibutani T, Nakao S, Matsumura K, Konomi T, Kondo K, Watanabe H (1999) SATARN system: a unified microseismic observation network in DPRI Kyoto University. Ann Disas Prev Res Inst Kyoto Univ 42(B-1):45-60

Omuralieva M, Hasegawa A, Matsuzawa T, Nakajima J, Okada T (2012) Lateral variation of the cutoff depth of shallow earthquakes beneath the Japan Islands and its implications for seismogenesis. Tectonophysics 518:93-105. https://doi.org/10.1016/j.tecto.2011.11.013

Sadikin N, Iguchi M, Suantika G, Hendrasto M (2007) Seismic activity of volcanotectonic earthquakes at Guntur volcano, West Java, Indonesia during the period from 1991 to 2005. Indones J Phys 18(1):21-28

Sano Y, Wakita H (1985) Geographical distribution of ${ }^{3} \mathrm{He} /{ }^{4} \mathrm{He}$ ratios in Japan: implications for arc tectonics and incipient magmatism. J Geophys Res 90:8729-8741. https://doi.org/10.1029/JB090iB10p08729

Sibson RH (1982) Fault zone models, heat flow and the depth distribution of earthquakes in the continental crust of the United States. Bull Seismol Soc Am 72:151-163

Suzuki H, Nakaya S (2012) Evolution of the Shimanto accretionary prism in the Kii peninsula, southwest Japan. Assoc Geol Collab Jpn Monogr 59:273-282 (in Japanese with English abstract)
Tanaka A, Yamamoto M, Yano Y, Sasada M (2004) Geothermal gradient and heat flow data in and around Japan (I): appraisal of heat flow from geothermal gradient data. Earth Planets Space 56:1191-1194. https://doi. org/10.1186/BF03353339

Terakawa T, Matsu'ura M (2010) The 3-D tectonic stress fields in and around Japan inverted from centroid moment tensor data of seismic events. Tectonics 29:TC6008. https://doi.org/10.1029/2009tc002626

Terakawa T, Hashimoto C, Matsu'ura M (2013) Changes in seismic activity following the 2011 Tohoku-oki earthquake: effects of pore fluid pressure. Earth Planet Sci Lett 365:17-24. https://doi.org/10.1016/j.epsl.2013.01.017

Umeda K, Ogawa Y, Asamori K, Oikawa T (2006) Aqueous fluids derived from a subducting slab: observed high ${ }^{3} \mathrm{He}$ emanation and conductive anomaly in a non-volcanic region, Kii Peninsula southwest Japan. J Volcanol Geotherm Res 149:47-61. https://doi.org/10.1016/j.jvolgeores.2005.06.005

Umino N, Matsuzawa T, Hori S, Nakamura A, Yamamoto A, Hasegawa A, Yoshida T (1998) 1996 Onikobe earthquakes and their relation to crustal structure. Zisin 51:253-264 (in Japanese with English abstract)

Urabe T, Tsukada S (1992) Win: a workstation program for processing waveform data from microearthquake networks. Prog Abstr Seismol Soc Jpn 2:41 (in Japanese)

Wada H, Ito K, Ohmi S, Hirano N, Koizumi M (2002) Linear distribution of seismicity in the Hida region. Ann Disas Prev Res Inst Kyoto Univ 45B:555-559 (in Japanese)

Wakita K (2013) Geology and tectonics of Japanese islands: a review-the key to understanding the geology of Asia. J Asian Earth Sci 72:75-87. https:// doi.org/10.1016/j.jseaes.2012.04.014

Wessel P, Smith W (1998) New, improved version of generic mapping tools released. EOS Trans AGU 79(47):579

Yao A (2012) The Chichibu and Kurosegawa terranes in the western part of the Kii Peninsula. J Geol Soc Jpn 118(Supplement):90-106

Yoshida A, Takayama H (1992) Correlation of seismic activities in the circumferential areas of the Kinki Triangle and its tectonic significance. J Geogr 101:327-335 (in Japanese with English abstract)

Yoshida A, Hosono K, Takayama H, Kobayashi A, Maeda K (2011) Seismic and geodetic evidence for the existence of hot materials beneath the Wakayama swarm activity, southwestern Japan. Tectonophysics 510:124-131. https://doi.org/10.1016/j.tecto.2011.06.023

Yoshida K, Hasegawa A, Okada T, Iinuma T, Ito Y, Asano Y (2012) Stress before and after the 2011 great Tohoku-oki earthquake and induced earthquakes in inland areas of eastern Japan. Geophys Res Lett 39:L03302. https://doi.org/10.1029/2011GL049729

Yoshida K, Hasegawa A, Okada T, linuma T (2014) Changes in the stress field after the 2008 M7.2 Iwate-Miyagi Nairiku earthquake in northeastern Japan. J Geophys Res Solid Earth 119:9016-9030. https://doi.org/10.1002 /2014JB011291

\section{Submit your manuscript to a SpringerOpen ${ }^{\odot}$ journal and benefit from:}

- Convenient online submission

- Rigorous peer review

- Open access: articles freely available online

- High visibility within the field

- Retaining the copyright to your article

Submit your next manuscript at springeropen.com 